\title{
Comunicação
}

\section{Cobertura morta e adubação orgânica na produção de alface e supressão de plantas daninhas}

\author{
Izabel Cristina Pereira Vaz Ferreira ${ }^{1}$, Alisson Vinicius de Araujo ${ }^{1}$, Altina Lacerda Nascimento ${ }^{2}$, \\ Thâmara Figueiredo Menezes Cavalcanti ${ }^{3}$,Leonardo David Tuffi Santos ${ }^{4}$
}

\begin{abstract}
RESUMO
Objetivou-se, neste trabalho, avaliar os efeitos da cobertura do solo e da adubação orgânica sobre a temperatura e a umidade do solo, a incidência de plantas daninhas e a produtividade da alface. O delineamento experimental utilizado foi de blocos casualizados, em esquema fatorial ( 3 x 3), em que o primeiro fator corresponde aos tipos de cobertura morta (capim tifton, capim napier e ausência de cobertura) e, o segundo, aos adubos (esterco bovino, esterco de galinhas e ausência de adubação). Analisaram-se as variáveis temperatura e umidade do solo, o número de folhas produzidas pela alface, as massas de matéria fresca e seca da parte aérea, das plantas de alface e daninhas, e o levantamento fitossociológico das plantas infestantes. As plantas adubadas com esterco de galinhas apresentaram massas de matéria fresca e seca superiores às das plantas não adubadas. A cobertura morta com capim tifton proporcionou aumento da massa de matéria seca das plantas de alface, o que pode estar relacionado com a menor temperatura dos canteiros que receberam esse material como cobertura. Commelina benghalensis foi a planta infestante mais importante no cultivo orgânico de alface. A aplicação de adubos orgânicos e a cobertura morta com capins não foram capazes de suprimir plantas daninhas e manter a umidade do solo, em áreas de cultivo de alface.
\end{abstract}

Palavras-chave: temperatura, umidade do solo, comunidade infestante, Commelina benghalensis L.

\section{ABSTRACT}

\section{Mulch and organic fertilizer in the production of lettuce and weed control}

This study aimed to assess the effects of mulch and organic fertilization on soil temperature and moisture, the incidence of weeds and yield of lettuce. The experimental design was a randomized block in a 3 x 3 factorial, including tifton, napier grass and lack of covering combined with cattle manure, chicken manure and no fertilizer. We analyzed the variables temperature and soil moisture, number of leaves produced per lettuce head, fresh weight and dry weight of lettuce shoots and weeds, and the phytosociological survey of infesting weed. Plants fertilized with chicken manure had greater fresh and dry weights compared to unfertilized plants. The application of tifton provided increased dry weight of lettuce, which may be associated with the lower temperature of plots that received this material as mulch. The species Commelina benghalensis was the most relevant weed in the organic cultivation. The application of organic fertilizers and mulch with grass was not able to suppress weeds and maintain soil moisture in areas of cultivation of lettuce.

Key words: temperature, soil moisture, weed community, Commelina benghalensis L.

Recebido para publicação em 10/12/2012 e aprovado em 06/05/2013.

'Engenheiros-Agrônomos, Mestres. Departamento de Fitotecnia, Universidade Federal de Viçosa, Campus Viçosa, Avenida Peter Henry Rolfs, s/n, $36570-000$ Viçosa, Minas Gerais,Brasil.izabelcpvf@yahoo.com.br (autora para correspondência); viniciusnca@yahoo.com.br

${ }^{2}$ Engenheira-Agrônoma, Mestre. Departamento de Solos e Nutrição de Plantas, Escola Superior de Agricultura "Luiz de Queiroz", Universidade de São Paulo, Avenida Pádua Dias, 11, 13418-900, Piracicaba, São Paulo, Brasil. altinalacerda@yahoo.com.br

${ }^{3}$ Engenheira-Agrônoma, Mestre. Instituto de Ciências Agrárias, Universidade Federal de Minas Gerais, Avenida Universitária, 1000, Bairro Universitário, 39404-006, Montes Claros, Minas Gerais, Brasil. thamara_fmc@yahoo.com.br (Bolsista de apoio técnico).

${ }^{4}$ Engenheiro-Agrônomo, Doutor. Instituto de Ciências Agrárias, Universidade Federal de Minas Gerais, Avenida Universitária, 1000, Bairro Universitário, 39404-006, Montes Claros, Minas Gerais, Brasil. Ituffi@yahoo.com.br 


\section{INTRODUÇÃO}

Em 2010, a Agência Nacional de Vigilância Sanitária do Brasil divulgou o relatório sobre o Programa de Análise de Resíduos de Agrotóxicos em Alimentos, no qual descreve que, dentre as amostras de alface coletadas, aproximadamente $54 \%$ estavam com resíduos de agrotóxicos, acima do nível permitido, ou com substâncias não autorizadas para o uso no cultivo de alface (ANVISA, 2011). A demanda por produtos orgânicos vem aumentando, não só pelo uso indiscriminado de agrotóxicos, mas também pelas crescentes restrições impostas por países importadores, gerando a necessidade de estudos de técnicas alternativas, que eliminem ou minimizem o uso de fertilizantes minerais, e de agrotóxicos, na produção de alimentos (Fontanétti et al., 2004).

A matéria orgânica é um excelente condicionador de solos, melhorando suas características físicas, químicas e biológicas, favorecendo a retenção de água, a agregação, a porosidade, a capacidade de troca de cátions, a fertilidade e a microbiota do solo. Em alface, diversos trabalhos, avaliando a aplicação de adubos orgânicos, foram realizados, constatando-se aumentos na produtividade e na qualidade dessa hortaliça (Cometti et al., 2004; Yuri et al., 2004; Abreu et al., 2010; Oliveira et al., 2010).

Para controle de plantas daninhas em cultivos olerícolas, tem-se pesquisado o uso de cobertura morta do solo. Segundo Trezzi \& Vidal (2004), esta prática pode reduzir a germinação das sementes de plantas daninhas por meio de fatores físicos, químicos e biológicos, e contribuir para o controle e, ou, a manutenção da temperatura e umidade do solo (Resende et al., 2005).

O manejo adequado de plantas daninhas é um fator determinante para a obtenção de melhores produtividades no cultivo da alface, uma vez que a competição entre as plantas resulta em perdas significativas. Trabalhos, realizados para avaliar o período total de prevenção da interferência, demonstram que, em cultivos de alface, esse tempo é, aproximadamente, de 21 dias e podem ocorrer prejuízos da ordem de $25 \%$ na produtividade (Giancotti et al., 2010).

Frente a essas informações, objetivou-se, com este trabalho, avaliar os efeitos da cobertura do solo e da adubação orgânica sobre a temperatura e a umidade do solo, a incidência de plantas daninhas e a produtividade da alface.

\section{MATERIAL E MÉTODOS}

O trabalho foi realizado, durante os meses de maio e junho de 2010, em Montes Claros, Minas Gerais, em área experimental localizada nas seguintes coordenadas geográficas: latitude $16^{\circ} 43^{\prime} \mathrm{S}$, longitude $43^{\circ} 53^{\prime} \mathrm{W}$ e altitude $650 \mathrm{~m}$, em região de clima Aw-tropical de savana, inverno seco e verão chuvoso, segundo Köppen. O solo é clas- sificado como Latossolo Vermelho e apresenta as seguintes características químicas, conforme análise: $\mathrm{pH}\left(\mathrm{H}_{2} \mathrm{O}\right)$ 7,7; 16,9 $\mathrm{mg} \mathrm{kg}^{-1}$ de P (Mehlich 1); 26,0 $\mathrm{mg} \mathrm{L}^{-1}$ de P remanescente; $353 \mathrm{mg} \mathrm{kg}^{-1}$ de $\mathrm{K}$; 8,8 cmolc $\mathrm{dm}^{-3}$ de $\mathrm{Ca} ; 1,2$ cmolc dm ${ }^{-3}$ de $\mathrm{Mg} ; 0,0$ cmolc dm ${ }^{-3}$ de Al; 0,89 cmolc dm $^{-3}$ de $\mathrm{H}+\mathrm{Al} ; 10,90 \mathrm{cmolc} \mathrm{dm}^{-3}$ de SB; $10,90 \mathrm{cmolc} \mathrm{dm}^{-3}$ de t; $0 \%$ de m; 11,80 cmolc dm ${ }^{-3}$ de T; $92 \%$ de V e 3,23 dag kg-1 de MO.

$\mathrm{O}$ experimento foi organizado em esquema fatorial $(3 \mathrm{x}$ 3 ), sendo o primeiro fator a cobertura morta e, o segundo, a adubação, em delineamento em blocos casualizados, com três repetições. O fator cobertura morta consistiu em capim tifton (Cynodon sp.) e em capim napier (Pennisetum purpureum Schumach.), colhidos antes da produção de sementes, picados em partículas de aproximadamente 1 $\mathrm{cm}$, e um tratamento sem cobertura do solo. As adubações utilizadas foram: esterco bovino $\left(50 \mathrm{Mg} \mathrm{ha}^{-1}\right)$, esterco de galinhas de postura (12 $\left.\mathrm{Mg} \mathrm{ha}^{-1}\right)$, conforme sugerido por Ribeiro et al. (1999), havendo ainda um tratamento sem adubação.

As sementes de alface, cv. Regina, foram semeadas inicialmente em bandejas de isopor e, após 20 dias, efetuouse o transplantio das mudas e a aplicação da cobertura morta nos canteiros. Os canteiros, preparados mecanicamente, apresentaram 1,0 m de largura e 0,20 m de altura e após este procedimento, incorporaram-se os adubos. Cada parcela foi constituída por 16 plantas, distribuídas em quatro fileiras, resultando área de $1 \mathrm{~m}^{2}$. Consideraram-se, como parcela útil, as quatro plantas centrais $\left(0,25 \mathrm{~m}^{2}\right)$. Durante a condução do experimento, não houve manejo de plantas daninhas e a irrigação foi realizada por microaspersão.

Semanalmente, a temperatura do solo de cada parcela foi aferida, utilizando-se termômetro digital específico, que foi inserido em quatro pontos, equidistantes, da parcela. As medições foram realizadas sempre às 13 horas, à profundidade de $5 \mathrm{~cm}$ da superfície do solo. A umidade do solo foi quantificada pelo método da diferença de massa. Concomitantemente às aferições da temperatura, coletaram-se amostras de solo no centro das parcelas, a $10 \mathrm{~cm}$ de profundidade, que foram acondicionadas em recipientes de metal e em caixa de isopor, levadas imediatamente ao laboratório e pesadas (massa inicial). As amostras eram, então, submetidas à secagem, em estufa de circulação forçada de ar, a uma temperatura de $105^{\circ} \mathrm{C}$, por $24 \mathrm{~h}$, ou massa constante, ponto no qual foram pesadas (massa final). Por fim, o teor de umidade do solo foi obtido pela diferença entre as massas do solo inicial e final das amostras, transformando o resultado em percentagem.

Completados 40 dias após o transplantio, computouse o número de folhas completamente expandidas por planta de alface. Após isso, as plantas de alface foram colhidas, acondicionadas em sacos plásticos e levadas ao laboratório para serem pesadas, determinando-se, dessa forma, a massa da matéria fresca da parte aérea das plantas. 
Para a determinação da massa da matéria seca, as plantas foram submetidas à secagem, em estufa de circulação forçada, a uma temperatura de $65^{\circ} \mathrm{C}$, até apresentarem massa constante.

Realizaram-se os levantamentos das espécies presentes na comunidade infestante, aos 15 e 40 dias após o transplante. Para isso, amostraram-se, em três pontos de cada sistema, por meio de um quadro vazado, de ferro, com dimensões de $0,5 \times 0,5 \mathrm{~m}$ (área interna de $0,25 \mathrm{~m}^{2}$ ), as plantas infestantes de cada sistema. Para análise da estrutura das comunidades de plantas daninhas, calcularam-se os seguintes caracteres fitossociológicos: frequência das espécies; densidade; abundância; frequência relativa, densidade relativa, abundância relativa e índice de valor de importância (IVI) (Mueller-Dombois \& Ellenberg, 1974). O IVI expressa numericamente a importância de uma determinada espécie na comunidade infestante. Determinou-se, também, a massa da matéria seca da parte aérea das plantas daninhas incidentes na parcela útil, realizando-se o mesmo procedimento adotado para a alface.

Os dados oriundos da contagem de folhas por planta, em alface, foram previamente transformados em $\sqrt{\mathrm{x}}$. Os dados foram submetidos à análise de variância pelo teste $\mathrm{F}$, e, quando significativas, as médias foram comparadas pelo teste de Tukey, a 5\% de probabilidade.

\section{RESULTADOS E DISCUSSÃO}

Não houve efeito da interação entre os fatores cobertura do solo e adubação, para nenhuma característica estudada. Para a variável número de folhas por planta de alface, também não se constatou influência dos fatores testados (Tabela 1). As plantas adubadas com esterco de galinha apresentaram massa de matéria fresca superior à das plantas não adubadas (Tabela 1). As adubadas com esterco bovino apresentaram um valor mediano, que não se diferenciou daquele dos demais tratamentos. No entanto, para a massa de matéria seca, foi verificada diferença significativa entre as plantas adubadas com esterco de galinha e com esterco bovino, sendo inferiores as massas referentes a este último tratamento. Isso pode ser justificado pelo fato de o esterco de aves apresentar maiores teores de nitrogênio e de fósforo que os do esterco bovino (Souza \& Resende, 2003). Além disso, o esterco de aves apresentou teores de celulose e relação $\mathrm{C} / \mathrm{N}$ mais baixos do que os do esterco bovino, o que aumenta a velocidade de decomposição do material e de mineralização de nutrientes (Souza \& Resende, 2003; Andreucci, 2007).

A aplicação de cobertura morta não alterou a produção de massa de matéria fresca e o número de folhas por planta, mas foi observado efeito desse tratamento sobre a massa de matéria seca, com o melhor resultado verificado com a aplicação de capim tifton (Tabela 1). Esse resultado parece não estar relacionado com a eficiência desse material no controle das plantas daninhas, visto que a massa seca da comunidade infestante não diminuiu com o uso desse tratamento (Tabela 1). A relação $\mathrm{C} / \mathrm{N}$ para o capim napier varia entre 29 e 30 (Sediyama et al., 1998) e, para o capim tifton, é de 30,9 (Zied et al., 2009), sendo, portanto, semelhantes, o que descarta a possibilidade de a massa de matéria seca produzida pela alface ter sido influenciada pelo tempo de decomposição desses materiais. Não obstante, verificou-se uma menor temperatura nos canteiros que receberam capim tifton como cobertura morta (Tabela 1). Essa menor temperatura pode ter favorecido o maior acúmulo de matéria seca pela alface, visto que essa cultura é sensível a esse fator (Porto et al., 1999; Filgueira 2003).

A umidade do solo não foi influenciada pelos fatores testados (Tabela 1). Esse resultado parece estar relacionado com a presença das plantas daninhas, que podem ter favorecido a manutenção da umidade nesses canteiros, funcionando como cobertura viva do solo. O que

Tabela 1. Massa da matéria seca (MMS) de plantas daninhas incidentes e temperatura e umidade do solo, número de folhas por planta de alface, massa da matéria fresca (MMF) e massa da matéria seca em plantas de alface cultivadas em áreas sob diferentes adubações orgânicas e coberturas mortas do solo

\begin{tabular}{|c|c|c|c|c|c|c|}
\hline Adubação & $\begin{array}{c}\text { MMS - planta } \\
\text { daninha (g) }\end{array}$ & $\begin{array}{c}\text { Temperatura } \\
\left({ }^{\circ} \mathbf{C}\right)^{*}\end{array}$ & Umidade $(\%)^{*}$ & $\begin{array}{c}\text { Folhas/planta } \\
\left(\mathbf{n}^{\mathbf{0}}\right)^{* *}\end{array}$ & $\begin{array}{c}\text { MMF -alface } \\
(\mathrm{g})^{*}\end{array}$ & $\begin{array}{c}\text { MMS - alface } \\
(\mathrm{g})^{*}\end{array}$ \\
\hline Sem adubação & $471,82^{\mathrm{ns}}$ & $24,12^{\text {ns }}$ & $12,40^{\text {ns }}$ & $3,46^{\text {ns }}(14,4)$ & $64,28 \mathrm{~b}$ & $2,66 b$ \\
\hline Esterco bovino & $345,44^{\mathrm{ns}}$ & $23,81^{\mathrm{ns}}$ & $12,29^{\mathrm{ns}}$ & $3,63^{\text {ns }}(14,9)$ & $70,44 \mathrm{ab}$ & $2,79 b$ \\
\hline Esterco de galinhas & $308,64^{\mathrm{ns}}$ & $23,92^{\text {ns }}$ & $11,78^{\text {ns }}$ & $4,20^{\text {ns }}(17,7)$ & $100,47 \mathrm{a}$ & $4,87 \mathrm{a}$ \\
\hline \multicolumn{7}{|l|}{ Cobertura morta } \\
\hline Sem cobertura & $485,16^{\mathrm{ns}}$ & $24,09 \mathrm{a}$ & $11,58^{\mathrm{ns}}$ & $3,90^{\text {ns }}(15,2)$ & $67,73^{\text {ns }}$ & $2,62 b$ \\
\hline Capim napier & $341,00^{\mathrm{ns}}$ & $24,05 \mathrm{a}$ & $12,39^{\text {ns }}$ & $3,96^{\text {ns }}(15,7)$ & $68,11^{\text {ns }}$ & $2,76 b$ \\
\hline Capim tifton & $299,74^{\text {ns }}$ & $23,72 b$ & $12,50^{\text {ns }}$ & $3,98^{\text {ns }}(15,9)$ & $99,34^{\text {ns }}$ & $4,93 \mathrm{a}$ \\
\hline $\mathrm{CV}(\%)$ & 72,65 & 1,09 & 7,82 & 9,69 & 37,11 & 45,28 \\
\hline
\end{tabular}

*Médias seguidas de mesma letra, na coluna, não diferem estatisticamente entre si pelo teste de Tukey a 5\% de probabilidade. **Médias oriundas da transformação dos dados em $\sqrt{\mathrm{x}}$. Valores entre parênteses correspondem às médias originais. ${ }^{\mathrm{ns}}$ não significativo pelo Teste $\mathrm{F}$. 
concorda com os dados de De-Polli et al. (1996), que verificaram que a cobertura viva reduz as perdas de água do solo por evaporação.

No primeiro levantamento da comunidade de plantas infestantes, realizada aos 15 dias após o transplantio das mudas, foram contabilizadas 32 espécies, de 13 famílias.
No segundo levantamento, aos 40 dias após transplante da alface, identificaram-se 30 espécies, de 14 famílias (Tabela 2). O grande número de espécies encontradas nesse levantamento está coerente com as informações relatadas por Carmona (1995) e Lacerda et al. (2005). Esses autores informaram que o banco de sementes é maior nas

Tabela 2. Frequência relativa (Frr), densidade relativa (Der), abundância relativa (Abr) e Índice de Valor de Importância (IVI) da comunidade infestante de canteiros de cultivo de alface que receberam cobertura morta de capim napier e tifton, e adubada com esterco bovino e de galinha, aos 15 e 40 dias após transplante das mudas

\begin{tabular}{|c|c|c|c|c|c|c|}
\hline Tratamento & Nome Científico & Família & Frr & Der & Abr & IVI \\
\hline \multicolumn{7}{|c|}{15 dias após transplante das mudas } \\
\hline \multirow{5}{*}{$\begin{array}{l}\text { Esterco de galinha }+ \\
\text { capim tifton }\end{array}$} & Amaranthus spp. & Amaranthaceae & 10,00 & 11,11 & 12,59 & 33,70 \\
\hline & Sonchus oleraceus L. & Asteraceae & 10,00 & 2,78 & 3,15 & 15,92 \\
\hline & Sinapis arvensis L. & Brassicaceae & 15,00 & 8,33 & 6,29 & 29,63 \\
\hline & Commelina benghalensis L. & Commelinaceae & 15,00 & 62,96 & 47,55 & 125,52 \\
\hline & Digitaria horizontalis Willd. & Poaceae & 10,00 & 2,78 & 3,15 & 15,92 \\
\hline \multirow{6}{*}{$\begin{array}{l}\text { Esterco de galinha }+ \\
\text { sem cobertura }\end{array}$} & Amaranthus spp. & Amaranthaceae & 5,71 & 6,36 & 7,72 & 19,80 \\
\hline & Bidens pilosa $\mathrm{L}$. & Asteraceae & 8,57 & 5,00 & 4,04 & 17,62 \\
\hline & S. oleraceus & & 8,57 & 3,64 & 2,94 & 15,15 \\
\hline & S. arvensis & Brassicaceae & 5,71 & 5,91 & 7,17 & 18,79 \\
\hline & C. benghalensis & Commelinaceae & 8,57 & 52,73 & 42,65 & 103,95 \\
\hline & D. horizontalis & Poaceae & 8,57 & 11,36 & 9,19 & 29,13 \\
\hline \multirow{4}{*}{$\begin{array}{l}\text { Esterco de galinha }+ \\
\text { capim napier }\end{array}$} & Amaranthus spp. & Amaranthaceae & 12,50 & 6,67 & 4,83 & 23,99 \\
\hline & S. arvensis & Brassicaceae & 12,50 & 5,71 & 4,14 & 22,35 \\
\hline & C. benghalensis & Commelinaceae & 12,50 & 62,86 & 45,52 & 120,87 \\
\hline & Malvastrum coromandelianum (L.) Garcke & Malvaceae & 8,33 & 5,71 & 6,21 & 20,25 \\
\hline \multirow{3}{*}{$\begin{array}{l}\text { Esterco bovino + } \\
\text { capim tifton }\end{array}$} & Amaranthus spp. & Amaranthaceae & 9,52 & 15,20 & 16,10 & 40,83 \\
\hline & S. arvensis & Brassicaceae & 4,76 & 4,00 & 8,47 & 17,24 \\
\hline & C. benghalensis & Commelinaceae & 14,29 & 64,80 & 45,76 & 124,85 \\
\hline \multirow{3}{*}{$\begin{array}{l}\text { Esterco bovino }+ \\
\text { sem cobertura }\end{array}$} & B. pilosa & Asteraceae & 10,00 & 2,96 & 2,42 & 15,38 \\
\hline & S. arvensis & Brassicaceae & 10,00 & 15,93 & 12,99 & 38,92 \\
\hline & C. benghalensis & Commelinaceae & 10,00 & 65,93 & 53,78 & 129,70 \\
\hline \multirow{5}{*}{$\begin{array}{l}\text { Esterco bovino + } \\
\text { capim napier }\end{array}$} & B. pilosa & Asteraceae & 9,09 & 9,09 & 8,28 & 26,46 \\
\hline & C. benghalensis & Commelinaceae & 13,64 & 52,53 & 31,90 & 98,06 \\
\hline & Euphorbia heterophylla L. & Euphorbiaceae & 4,55 & 4,04 & 7,36 & 15,95 \\
\hline & Zea mays L. & Poaceae & 4,55 & 14,14 & 25,77 & 44,45 \\
\hline & M. coromandelianum & Malvaceae & 9,09 & 6,06 & 5,52 & 20,67 \\
\hline \multirow{4}{*}{$\begin{array}{l}\text { Sem adubação + } \\
\text { capim napier }\end{array}$} & Amaranthus spp. & Amaranthaceae & 8,70 & 3,42 & 4,00 & 16,11 \\
\hline & B. pilosa & Asteraceae & 13,04 & 11,11 & 8,67 & 32,82 \\
\hline & S. avernsis & Brassicaceae & 8,70 & 3,42 & 4,00 & 16,11 \\
\hline & C. benghalensis & Commelinaceae & 13,04 & 65,81 & 51,33 & 130,19 \\
\hline \multirow{6}{*}{$\begin{array}{l}\text { Sem adubação + } \\
\text { capim tifton }\end{array}$} & Amaranthus spp. & Amaranthaceae & 9,52 & 6,32 & 6,12 & 21,96 \\
\hline & B. pilosa & Asteraceae & 9,52 & 5,26 & 5,10 & 19,89 \\
\hline & S. arvensis & Brassicaceae & 9,52 & 12,63 & 12,24 & 34,40 \\
\hline & C. benghalensis & Commelinaceae & 14,29 & 50,53 & 32,65 & 97,47 \\
\hline & E. heterophylla & Euphorbiaceae & 4,76 & 4,21 & 8,16 & 17,14 \\
\hline & Malva spp. & Malvaceae & 9,52 & 5,26 & 5,10 & 19,89 \\
\hline \multirow{5}{*}{$\begin{array}{l}\text { Sem adubação + } \\
\text { sem cobertura }\end{array}$} & B. pilosa & Asteraceae & 8,82 & 5,96 & 4,69 & 19,47 \\
\hline & S. oleraceus & & 8,82 & 3,83 & 3,02 & 15,67 \\
\hline & S. arvensis & Brassicaceae & 8,82 & 14,89 & 11,73 & 35,44 \\
\hline & C. benghalensis & Commelinaceae & 8,82 & 50,64 & 39,87 & 99,33 \\
\hline & M. coromandelianum & Malvaceae & 5,88 & 5,11 & 6,03 & 17,02 \\
\hline
\end{tabular}




\begin{tabular}{|c|c|c|c|c|c|c|}
\hline Tratamento & Nome Científico & Família & Frr & Der & Abr & IVI \\
\hline \multicolumn{7}{|c|}{40 dias após o transplante das mudas } \\
\hline \multirow{6}{*}{$\begin{array}{l}\text { Esterco de galinha }+ \\
\text { capim tifton }\end{array}$} & Amaranthus spp. & Amaranthaceae & 7,41 & 11,11 & 10,29 & 28,80 \\
\hline & S. oleraceus & Asteraceae & 11,11 & 6,48 & 4,00 & 21,59 \\
\hline & C. benghalensis & Commelinaceae & 7,41 & 50,00 & 46,29 & 103,69 \\
\hline & Sida rhombifolia $\mathrm{L}$. & Malvaceae & 7,41 & 6,48 & 6,00 & 19,89 \\
\hline & D. horizontalis & Poaceae & 11,11 & 4,63 & 2,86 & 18,60 \\
\hline & Physalis angulata $\mathrm{L}$. & Solanaceae & 11,11 & 3,70 & 2,29 & 17,10 \\
\hline \multirow{6}{*}{$\begin{array}{l}\text { Esterco de galinha }+ \\
\text { sem cobertura }\end{array}$} & Amaranthus spp. & Amaranthaceae & 4,88 & 7,99 & 9,16 & 22,03 \\
\hline & B. pilosa & Asteraceae & 7,32 & 4,44 & 3,39 & 15,15 \\
\hline & S. arvensis & Brassicaceae & 2,44 & 4,44 & 10,18 & 17,06 \\
\hline & C. benghalensis & Commelinaceae & 7,32 & 42,01 & 32,13 & 81,46 \\
\hline & S. rhombifolia & Malvaceae & 7,32 & 5,03 & 3,85 & 16,19 \\
\hline & D. horizontalis & Poaceae & 7,32 & 19,23 & 14,71 & 41,25 \\
\hline \multirow{6}{*}{$\begin{array}{l}\text { Esterco de galinha }+ \\
\text { capim napier }\end{array}$} & Alternanthera ficoidea (L.) P. Beauv. & Amaranthaceae & 9,68 & 5,50 & 4,15 & 19,33 \\
\hline & Amaranthus spinosus $\mathrm{L}$. & & 3,23 & 2,75 & 6,23 & 12,21 \\
\hline & B. pilosa & Asteraceae & 6,45 & 6,42 & 7,27 & 20,14 \\
\hline & S. arvensis & Brassicaceae & 9,68 & 8,26 & 6,23 & 24,16 \\
\hline & C. benghalensis & Commelinaceae & 9,68 & 51,38 & 38,75 & 99,81 \\
\hline & D. horizontalis & Poaceae & 9,68 & 8,26 & 6,23 & 24,16 \\
\hline \multirow{4}{*}{$\begin{array}{l}\text { Esterco bovino }+ \\
\text { capim tifton }\end{array}$} & Amaranthus spp. & Amaranthaceae & 6,90 & 5,99 & 6,38 & 19,27 \\
\hline & Amaranthus deflexus L. & & 3,45 & 4,19 & 8,94 & 16,58 \\
\hline & Galinsoga parviflora Cav. & Asteraceae & 10,34 & 3,59 & 2,55 & 16,49 \\
\hline & C. benghalensis & Commelinaceae & 10,34 & 65,27 & 46,38 & 122,00 \\
\hline \multirow{4}{*}{$\begin{array}{l}\text { Esterco bovino }+ \\
\text { sem cobertura }\end{array}$} & S. arvensis & Brassicaceae & 5,77 & 9,03 & 7,86 & 22,66 \\
\hline & C. benghalensis & Commelinaceae & 5,77 & 58,26 & 50,67 & 114,69 \\
\hline & Sida urens L. & Malvaceae & 21,15 & 0,62 & 0,15 & 21,92 \\
\hline & D. horizontalis & Poaceae & 5,77 & 7,48 & 6,50 & 19,75 \\
\hline \multirow{5}{*}{$\begin{array}{l}\text { Esterco bovino + } \\
\text { capim napier }\end{array}$} & B. pilosa & Asteraceae & 10,34 & 12,37 & 9,41 & 32,13 \\
\hline & C. benghalensis & Commelinaceae & 10,34 & 55,67 & 42,35 & 108,37 \\
\hline & Ipomoea triloba $\mathrm{L}$. & Convolvulaceae & 10,34 & 2,06 & 1,57 & 13,98 \\
\hline & E. heterophylla & Euphorbiaceae & 3,45 & 4,12 & 9,41 & 16,98 \\
\hline & D. horizontalis & Poaceae & 6,90 & 5,15 & 5,88 & 17,93 \\
\hline \multirow{6}{*}{$\begin{array}{l}\text { Sem adubação + } \\
\text { capim napier }\end{array}$} & A. ficoidea & Amaranthaceae & 9,09 & 3,45 & 2,75 & 15,29 \\
\hline & Amaranthus spp. & & 6,06 & 4,14 & 4,95 & 15,14 \\
\hline & B. pilosa & Asteraceae & 9,09 & 6,21 & 4,95 & 20,24 \\
\hline & S. arvensis & Brassicaceae & 9,09 & 6,21 & 4,95 & 20,24 \\
\hline & C. benghalensis & Commelinaceae & 9,09 & 60,00 & 47,80 & 116,89 \\
\hline & D. horizontalis & Poaceae & 6,06 & 4,14 & 4,95 & 15,14 \\
\hline \multirow{5}{*}{$\begin{array}{l}\text { Sem adubação + } \\
\text { capim tifton }\end{array}$} & A. ficoidea & Amaranthaceae & 8,70 & 3,50 & 3,73 & 15,92 \\
\hline & Amaranthus spp. & & 8,70 & 3,50 & 3,73 & 15,92 \\
\hline & B. pilosa & Asteraceae & 13,04 & 5,59 & 3,98 & 22,62 \\
\hline & S. arvensis & Brassicaceae & 8,70 & 19,58 & 20,90 & 49,17 \\
\hline & C. benghalensis & Commelinaceae & 13,04 & 51,05 & 36,32 & 100,41 \\
\hline \multirow{7}{*}{$\begin{array}{l}\text { Sem adubação + } \\
\text { sem cobertura }\end{array}$} & B. pilosa & Asteraceae & 7,69 & 6,12 & 4,78 & 18,59 \\
\hline & Emilia fosbergii Nicolson & & 5,13 & 4,68 & 5,49 & 15,29 \\
\hline & G. parviflora & & 7,69 & 6,47 & 5,06 & 19,23 \\
\hline & S. arvensis & Brassicaceae & 7,69 & 15,47 & 12,10 & 35,26 \\
\hline & C. benghalensis & Commelinaceae & 7,69 & 36,69 & 28,69 & 73,07 \\
\hline & S. rhombifolia & Malvaceae & 5,13 & 6,83 & 8,02 & 19,98 \\
\hline & D. horizontalis & Poaceae & 7,69 & 7,55 & 5,91 & 21,15 \\
\hline
\end{tabular}

Rev. Ceres, Viçosa, v. 60, n.4, p. 582-588, jul/ago, 2013 
áreas mais perturbadas e que práticas baseadas na movimentação das camadas do solo aumentam a distribuição de plantas, nas áreas de cultivo e no perfil do solo, permitindo que as sementes permaneçam próximas à superfície. Esse fato pode aumentar a germinação de sementes de plantas daninhas (Ball, 1992).

Verificou-se também, superioridade da incidência das eudicotiledôneas, no primeiro e segundo levantamentos, em relação à das monocotiledôneas, o que também foi observado por Reghin et al. (2002), em cultivos de alface. Os sistemas em que não se efetuou a prática de cobertura morta apresentaram menores valores de IVI, no primeiro levantamento (Tabela 2), destacando-se a menor abundância relativa detectada nesses canteiros, principalmente, para a Commelina benghalensis. Dentre os adubos orgânicos avaliados, os canteiros que receberam esterco de galinha apresentaram menor IVI, no primeiro levantamento, enquanto, nos canteiros adubados com esterco bovino, esses valores foram semelhantes aos dos canteiros sem adubação (Tabela 2). Este resultado pode ter sido fruto do maior teor e da maior velocidade de mineralização de nutrientes do esterco de galinha, em relação aos do esterco bovino, o que pode ter melhorado o ambiente de competição para outras plantas daninhas, em relação a Commelina benghalensis.

No segundo levantamento, os canteiros cobertos com capim napier apresentaram menor IVI, quando adubados com esterco bovino. Já o capim tifton mostrou IVI menor que os das demais coberturas, quando colocado em canteiro sem adubação (Tabela 2).

Destaca-se a maior dominância da espécie Commelina benghalensis (trapoeraba), em todos os sistemas analisados, com maior IVI, pela maior densidade relativa e pela abundância relativa, quando comparada com as das demais espécies. Este resultado reflete a característica de dominância que a trapoeraba apresenta frente às demais espécies que ocorreram na área. Conforme Rodrigues \& Pitelli (1994), essa é uma espécie que, além de produzir sementes, na parte aérea, também pode-se propagar por rizomas, o que facilita a permanência e disseminação da espécie por toda a área de cultivo. De acordo com Gomes Junior \& Christoffoleti (2008), as espécies perenes, como a $C$. benghalensis, são favorecidas pelas práticas utilizadas no plantio direto, que não expõem seus órgãos vegetativos à dessecação.

\section{CONCLUSÕES}

A aplicação de esterco de galinha aumenta a produção da alface. Já o capim tifton é mais eficiente que o napier no controle da temperatura do solo. A cobertura morta, com capim tifton ou napier, não é capaz de suprimir plantas daninhas e manter a umidade do solo.

\section{REFERÊNCIAS}

Abreu IMO, Junqueira AMR, Peixoto JR \& Oliveira SA (2010) Qualidade microbiológica e produtividade de alface sob adubação química e orgânica. Ciência e Tecnologia Agroindustrial, 30:108-118.

Andreucci MP (2007) Perdas nitrogenadas e recuperação aparente de nitrogênio em fontes de adubação de capim elefante. Dissertação de Mestrado. Escola Superior de Agricultura "Luiz de Queiroz", Piracicaba. 104p.

ANVISA (2011) Programa de análise de resíduos de agrotóxicos em alimentos (PARA): Relatório de atividades de 2010. Brasília, ANVISA. 26p.

Ball DA (1992) Weed seedbank response to tillage, herbicides, and crop rotation sequence. Weed Sciense, 14:654-659.

Carmona R (1995) Banco de sementes e estabelecimento de plantas daninhas em agroecossistemas. Planta Daninha, 13:3-9.

Cometti NN, Matias GCS, Zonta E, Mary W \& Fernandes MS (2004) Composto nitrogenado e açucares solúveis em tecidos de alface orgânica, hidropônica e convencional. Horticultura Brasileira, 22:748-753.

De-Polli H, Guerra JGM, Almeida DL de \& Franco AA (1996) Adubação verde: parâmetros para avaliação de sua eficiência. In: Castro Filho C de \& Muzilli O (Eds.) Manejo integrado de solos em microbacias hidrográficas. Londrina, Iapar/SBCS. p.225-242.

Filgueira FAR (2003) Novo manual de olericultura: Agrotecnologia moderna na produção e comercialização de hortaliças. $2^{a}$ ed. Viçosa, UFV. 412p.

Fontanétti A, Carvalho GJ, Morais AR, Almeida K \& Duarte WF (2004) Adubação verde no controle de plantas invasoras nas culturas de alface-americana e de repolho. Ciência e Agrotecnologia, 28:967-973.

Giancotti PRF, Machado MH \& Yamauti MS (2010) Período total de prevenção a interferência das plantas daninhas na cultura da alface cultivar Solaris. Semina: Ciências Agrárias, 31:1299-1304.

Gomes Junior FG \& Christoffoleti PJ (2008) Biologia e manejo de plantas daninhas em áreas de plantio direto. Planta Daninha, 26:789-798.

Lacerda ALS, Victoria Filho R \& Mendonça CG (2005) Levantamento do banco de sementes em dois sistemas de manejo de solo irrigados por pivô central. Planta Daninha, 23:1-7.

Mueller-Dombois D \& Ellenberg HA (1974) Aims and methods of vegetation ecology. New York, Jonh Wiley. 547p.

Oliveira EQ, Souza RJ, Cruz MCM, Marques VB \& França AC (2010) Produtividade de alface e rúcula, em sistema consorciado, sob adubação orgânica e mineral. Horticultura Brasileira, 28:36-40.

Porto VCN, Negreiros MZ, Neto FB \& Nogueira ICC (1999) Fontes e doses de matéria orgânica na produção de alface. Revista Caatinga, 12:07-11.

Reghin MY, Purissimo C, Feltrim AL \& Foltran MA (2002) Produção de alface utilizando cobertura do solo e proteção das plantas. Scientia Agraria, 3:69-77.

Resende FV, Souza LS, Oliveira PSR \& Gualberto R (2005) Uso de cobertura morta vegetal no controle da umidade e temperatura do solo, na incidência de plantas invasoras e na produção da cenoura em cultivo de verão. Ciência e Agrotecnologia, 29:100105 .

Ribeiro AC, Guimarães PTG \& Alvarez V VH (1999) Recomendações para o uso de corretivos e fertilizantes em Minas Gerais. $5^{\text {a }}$ aproximação. Viçosa, Comissão de Fertilidade do Solo do Estado de Minas Gerais. 359p.

Rev. Ceres, Viçosa, v. 60, n.4, p. 582-588, jul/ago, 2013 
Rodrigues BN \& Pitelli RA (1994) Quebra de dormência em sementes de Commelina benghalensis. Planta Daninha, 12:106110 .

Sediyama MAN, Vidigal SM, Pereira PRG, Garcia NCP \& Lima PC (1998) Produção e composição mineral de cenoura adubada com resíduos orgânicos. Bragantia, 57:379-386.

Souza JL \& Resende P (2003) Manual de horticultura orgânica. Viçosa, Aprenda Fácil. 564p.

Trezzi MM \& Vidal RA (2004) Potencial de utilização de cobertura vegetal de sorgo e milheto na supressão de plantas daninhas m condição de campo: II - Efeitos da cobertura morta. Planta Daninha, 22:01-10.
Yuri JE, Resende GM, Rodrigues Júnior JC, Mota JH \& Souza RJ (2004) Efeito de composto orgânico sobre a produção e características comerciais de alface americana. Horticultura Brasileira, 22:127-130.

Zied DC, Minhoni MTA, Kopytowski Filho J, Arruda DP \& Andrade MCN (2009) Produção de Agaricus blazei ss. Heinemann (A. brasiliensis) em função de diferentes camadas de cobertura e substratos de cultivo. Interciencia, 34:437-442. 